\title{
The Incorporation of n-3 and n-6 Essential Fatty Acids into the Chick Embryo from Egg Yolks Having Vastly Different Fatty Acid Compositions
}

\author{
DON S. LIN, WILLIAM E. CONNOR, AND GREGORY J. ANDERSON \\ Division of Endocrinology: Diabetes and Clinical Nutrition, Department of Medicine, Oregon Health Sciences \\ Universit1: Portland, Oregon $97201-3098$
}

\begin{abstract}
The effect of egg yolk fatty acid composition on essential fatty acid utilization by the developing chick embryo was studied by feeding laying hens a fat-free diet supplemented with oils containing widely divergent contents of the essential n-6 and n-3 fatty acids. A control hen was fed a commercial feed for laying hens. The diets contained 20 to $4370 \mathrm{mg} / 100 \mathrm{~g} \mathrm{n}-3$ fatty acids and 360 to $8020 \mathrm{mg} / 100 \mathrm{~g}$ n-6 fatty acids. Fertile eggs were collected in pairs: one was incubated and the other served as an unincubated control. The fatty acid content of the unincubated egg and the newly hatched chick from each pair was compared. Some $\mathbf{5 0 \%}$ of the total fatty acids in the egg yolk were incorporated into the tissues of the newly hatched chick. Regardless of diet, more yolk n-6 fatty acids were incorporated into the chick compared to saturated or monounsaturated fatty acids. The percentage of incorporation especially increased from the eggs containing relatively low amounts of $n-6$ fatty acids. The percentage of incorporation of $n-3$ fatty acids was similar to that of saturated and monounsaturated fatty acids when n-3 fatty acids were plentiful in the egg yolk, but increased significantly when n-3 fatty acids were low in the eggs. There was a generally linear relationship between essential fatty acids in the egg and in the chick, although levels of docosahexaenoic acid [DHA; 22:6(n-3)] in the brain did not respond proportionally. The developing chick preferentially removed DHA from the yolk, but did not synthesize more DHA when the amount of the DHA precursor, 18:3(n-3), in the yolk was increased. We concluded that the developing chick embryo requires $0.4-1.1 \%$ of egg energy as n-3 fatty acids and $4.8-6.2 \%$ as n-6 fatty acids, or a "dietary" ratio of $n-6 / n-3$ of 5 to 14 . This requirement may have relevance for humans as well. (Pediatr Res 29: $601-605,1991)$
\end{abstract}

\section{Abbreviations}

DHA, docosahexaenoic acid

The essentiality of $n-6$ fatty acids was established over 50 years tgo $(1,2)$. Now a growing body of evidence indicates that $n-3$ atty acids have their own distinctive role in the structure and unction of biologic membranes, particularly in the retina and ZNS (3). Depriving rats of dietary n-3 fatty acids for two gener-

Received October 30. 1990; accepted February 13, 1991

Correspondence: William E. Connor. M.D.. Department of Medicine, L465. he Oregon Health Sciences University. Portland. OR 97201-3098.

Supported by NIH Grants HL-07295. HL-25687. HL-37940. DK-29930. DK0935. and RR-00334 and a research fellowship (G.J.A.) from the American Heart ssociation. Oregon Afiliatc. ations, Yamamoto et al. $(4,5)$ and Bourre et al. (6) reported a significantly lower learning ability in the deficient animals. Feeding pregnant monkeys an n-3 fatty acid-deficient diet, we found that the resulting infants suffered visual impairment, had abnormal electroretinograms, and developed polydipsia (7-10).

Unlike mammals, the chicken has a unique reproductive system that is self-contained with regard to nutrients. Lipid-rich egg yolk is the chief source of nutrients for the avian embryo (11). This biologically self-sufficient model allows a close correlation between nutritive substances and their physiologic utilization. In a previous study, we demonstrated that dietary fats of the laying hen can drastically alter the fatty acid composition of the egg and, in turn, that of the newborn chick (12). In our present study, we quantitatively examined the relative contribution of essential fatty acids to embryo formation when the egg yolk contained vastly differing amounts of both n-6 and n-3 fatty acids.

\section{MATERIALS AND METHODS}

Five single-comb White Leghorn laying hens (commercial strain) were housed individually under $16 \mathrm{~h}$ light/d as approved by the University Animal Care Committee. Each hen was fed a different diet: four of the hens were fed a semipurified fat-free basal mix (12) $(62.53 \%$ dextrose, $20.78 \%$ fat-free casein, $0.39 \%$ L-arginine, $0.39 \%$ DL-methionine, $3.33 \%$ cellulose, $12.20 \%$ salt mix, $0.38 \%$ vitamin mix, and $10 \%$ fat; Teklad, Madison, WI) containing $10 \%$ (wt/wt) of safflower oil, soy oil, linseed oil, or fish oil (MaxEPA; Seven Sea Limited, Hull, UK), respectively, and the remaining hen was fed a commercial diet for laying hens containing $3 \%$ fat and consisting principally of corn mash. These diets differed greatly in their fatty acid composition and content (Table 1). The safflower oil diet had a very high content of $n-6$ fatty acids ( $80 \%$ of total fatty acids) and very little of the n-3 fatty acids $(0.2 \%)$. At the other extreme, both the fish and linseed oil diets had a high content of n-3 fatty acids (34 and $44 \%$, respectively). Fish oil is rich in longer chain $\left(\geq C_{20}\right) n-3$ fatty acids, but linseed oil contains only linolenic acid [18:3(n-3)]. In preparing the diets, the various oils were mixed thoroughly with the powdered basal mixes. Diets were stored at $4^{\circ} \mathrm{C}$ and made fresh weekly, and the feed cups were changed daily. Precautions were taken to minimize oxidation of the polyunsaturated fatty acids (12).

Every other night, a White Leghorn rooster was placed in the cage with the laying hens for insemination. Fertile eggs were collected daily from these hens after they had consumed their respective diets for 1 mo (12), by which time the fatty acid composition of the eggs had stabilized. Eggs laid on adjacent days were collected in pairs: one egg was incubated and the other (unincubated) egg was analyzed as a control to represent the lipid composition of the egg yolk before incubation. For each diet, six pairs of eggs were collected. Eggs were incubated in a Marsh 
Roll-X automatic incubator at $98-99^{\circ} \mathrm{F}$. The various experimental diets produced no differences in egg production, fertility, or hatchability.

Chicks were killed within $12 \mathrm{~h}$ of hatching and were not fed. Lipids were extracted from the brain, yolk sac contents, carcass, and the egg yolk of unincubated control eggs by the method of Folch et al. (13). The carcass was first cut into small pieces, homogenized in a Waring blender, and extracted five times. Antioxidant (butylated hydroxytoluene) was added to all lipid extracts (14). The fatty acid composition of the various samples was determined by capillary gas-liquid chromatography as described before (12). For quantitative fatty acid determinations, heptadecanoic acid (17:0) was added to duplicate aliquots as an internal standard. Recovery of DHA was verified by parallel analysis of an external standard. For data reported as whole chick, the values for the carcass, brain, and yolk sac were added together.

Percentage of incorporation of a fatty acid into the chick is defined as the amount of that fatty acid recovered in the newly hatched chick divided by the amount present in a paired egg that was not incubated. This calculation does not, however, give a straightforward measurement of the transfer of fatty acids from egg to chick. For example, because the chick embryo is able to desaturate and elongate fatty acids $(15,16)$, a portion of a "recovered" fatty acid in the chick might be derived from a precursor fatty acid in the egg yolk. Similarly, a portion of a given fatty acid in the egg yolk could be metabolized to longerchain or more unsaturated products. In addition, the developing chick derives most of its energy from oxidation of yolk fatty acids $(11,17)$. Thus, the "percentage of incorporation" defined here represents a net balance between anabolic, catabolic, and transport processes.

Comparison of the effect of diet on the incorporation of fatty acids from egg to the tissues of the chick was correlated by analysis of variance. Comparison of the incorporation of saturated, monounsaturated, $n-6$, and $n-3$ fatty acids within a given diet was performed by repeated measures analysis of variance. Differences between individual means were detected by use of the appropriate $t$ statistic (18), using the Bonferroni inequality (19) to control the overall $\alpha$-level.

\section{RESULTS}

The relative conservation of essential fatty acids during the utilization of egg yolk lipids by the developing chick embryo can be seen in Table 2. Regardless of the essential fatty acid content of the diet, a higher percentage of total $n-6$ fatty acids, as opposed to either saturated or monounsaturated fatty acids, was incorporated into the chick $(p<0.02)$. The $\mathrm{n}-3$ fatty acids were also preferentially incorporated, but only in the two diet groups (control and safflower oil) that had the lowest levels of n-3 fatty acids in the egg. In general, changing the amount of total n-6 and total n-3 fatty acids in the egg led to reciprocal effects on the incorporation of $n-6$ and $n-3$ fatty acids. Thus, when $n-6$ fatty acids in the egg were low and n-3 fatty acids were high (fish and linseed oil diets), incorporation of total $n-6$ fatty acids was high $(64 \%)$ and incorporation of total n-3 fatty acids was lower (54 and $51 \%$, respectively). And when n-3 fatty acids were low (control and safflower oil diets) incorporation of n-3 fatty acids was high (66 and $74 \%$, respectively). This reciprocal effect was particularly pronounced in the case of 20:4(n-6) and DHA, where the feeding of the fish and safflower oil diets caused so little 20:4(n-6) and DHA, respectively, to be deposited in the egg that the developing chick retained $>80 \%$ of the fatty acids originally present in the yolk. Of course, some of this apparent incorporation of these long-chain polyunsaturates could have been due to synthesis from 18 carbon precursors, i.e. 18:2(n-6) and 18:3(n$3)$. This is likely not the sole explanation, inasmuch as the amount of 18:2 and 18:3 incorporated into the fish oil and safflower oil chicks, respectively, was not low relative to the other diets. An effect of diet on the apparent incorporation of 22:4(n6) clearly was due to synthesis from precursors, however. In this case, more 22:4(n-6) was recovered in the chick than was present in the egg, resulting in an incorporation rate greater than $100 \%$.

The incorporation of total n-6 and total n-3 fatty acids into the chick is displayed graphically in Figure 1, where the trend toward a reciprocal relationship between diet and incorporation can be seen clearly.

Despite differences in the percentage of incorporation of essential fatty acids into the chick, there was a generally linear relationship between the amount of n-6 and n-3 fatty acids in the egg and in the chick $(r=0.83, p<0.001$ for $\mathrm{n}-3 ; r=0.93, p<$ 0.001 for $n-6$ ). However, not all chick tissues responded to higher amounts of $n-3$ fatty acids in the egg. Brain levels of DHA did not respond proportionally when the amount of DHA in the egg was increased beyond that found in the eggs produced on the soybean oil diet. This is shown graphically in Figure 2, where the amount of DHA in the egg is displayed in conjunction with the amount of DHA found in the whole chick and in the brain alone.

The extremely high levels of 18:3 in the eggs of hens fed the linseed oil diet did not lead to any real increase in the amount of DHA found in the chick compared to eggs from the soy diet (Fig. $3 A$ ). In fact, the very small increase in whole chick DHA that was measured in the linseed versus the soy chicks could be attributed to the slightly higher levels of "preformed" DHA in the eggs of the linseed oil hens (Fig. 3B).

The utilization of fatty acids by the developing chick embryo was further studied by examining the residual yolk contained in the yolk sac of the newly hatched chick. The fatty acid composition of this material is compared in Table 3 with that of the control unincubated egg yolk. It is apparent that DHA and 20:4 were preferentially absorbed from the yolk during incubation. This effect was seen in all five diets.

Table 1 . Fatty acid content ( $\mathrm{mg} / \mathrm{l} 00 \mathrm{~g}$ diet) and fatty acid composition (weight \%) of experimental diets*

\begin{tabular}{|c|c|c|c|c|c|}
\hline & Control & Safflower oil & Soy oil & Fish oil & Linseed oil \\
\hline Total fatty acid & 2976 & 10010 & 9980 & 9590 & 9940 \\
\hline Saturated & $405(13.5)$ & $890(8.9)$ & $1610(16.1)$ & $2970(29.7)$ & $1170(11.7)$ \\
\hline Monounsaturated & $759(25.3)$ & $1080(10.3)$ & $2280(22.8)$ & $2840(28.4)$ & $2230(22.3)$ \\
\hline Polyunsaturated & $1812(60.4)$ & $8040(80.4)$ & $6110(61.1)$ & $3780(37.8)$ & $6570(65.7)$ \\
\hline Total $n-6$ & $1764(58.8)$ & $8020(80.2)$ & $5450(54.5)$ & $360(3.6)$ & $2170(21.7)$ \\
\hline $18: 2(n-6)$ & $1746(58.2)$ & $7990(79.9)$ & $5450(54.5)$ & $170(1.7)$ & $2170(21.7)$ \\
\hline $20: 4(n-6)$ & & & & $110(1.1)$ & \\
\hline Total n-3 & $48(1.6)$ & $20(0.2)$ & $630(6.3)$ & $3420(34.2)$ & $4370(43.7)$ \\
\hline $18: 3(n-3)$ & $42(1.4)$ & $20(0.2)$ & $630(6.3)$ & $70(0.7)$ & $4370(43.7)$ \\
\hline $20: 5(n-3)$ & & & & $1640(16.4)$ & \\
\hline $22: 5(n-3)$ & & & & $280(2.8)$ & \\
\hline $22: 6(n-3)$ & & & & $1100(11.0)$ & \\
\hline Ratio $n-6 / n-3$ & 36.8 & 401 & 8.7 & 0.1 & 0.5 \\
\hline
\end{tabular}

\footnotetext{
* Fatty acid composition (\%) is given in parentheses.
} 


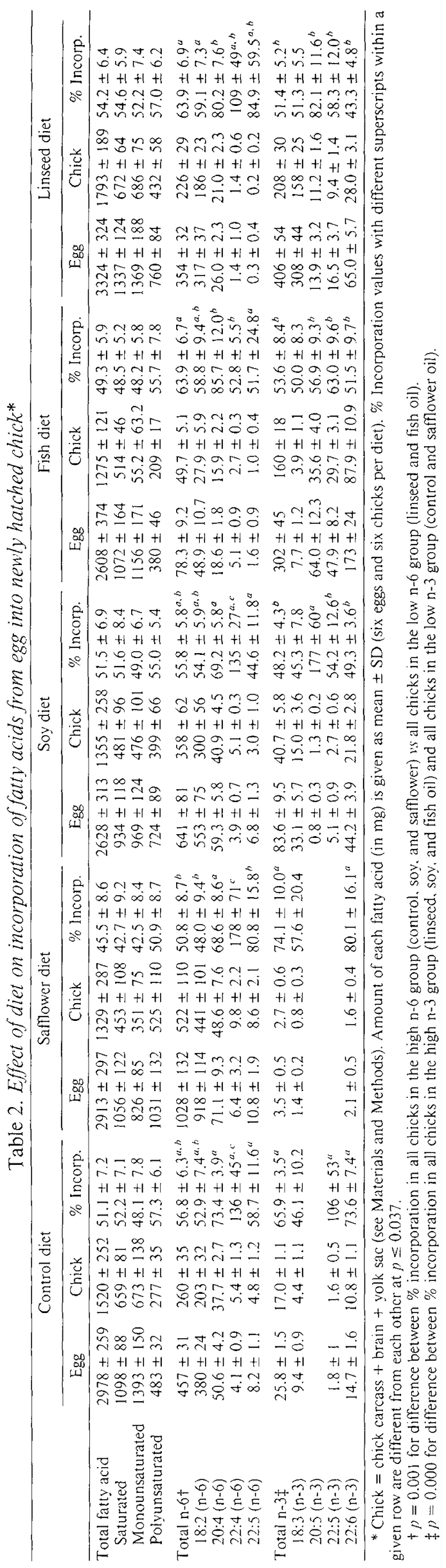

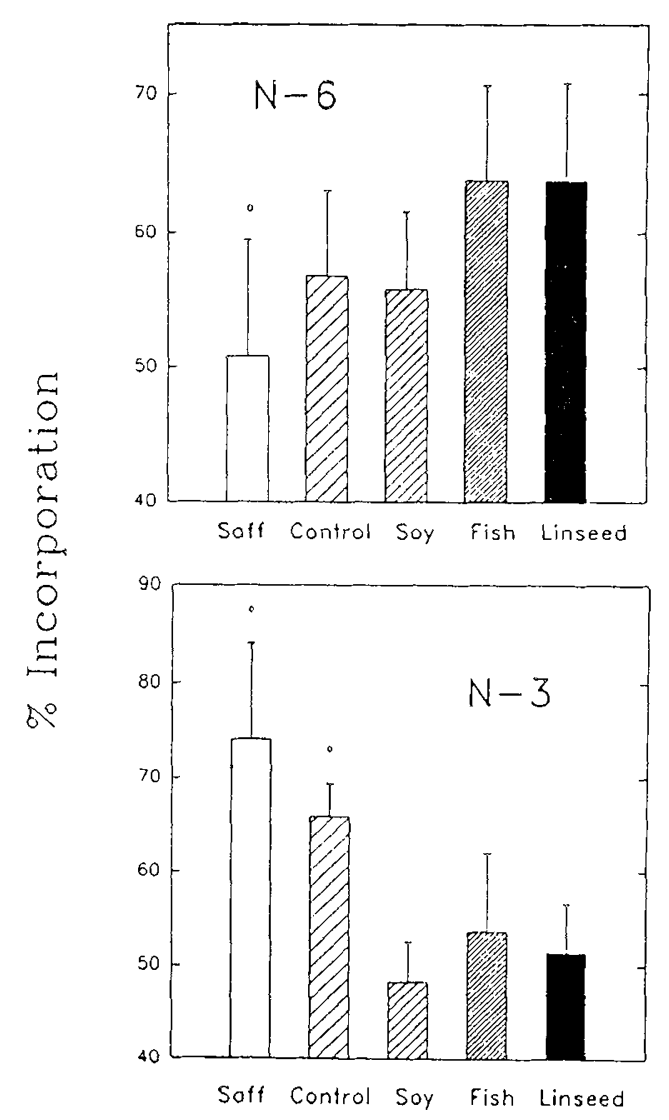

Fig. 1. Effect of diet on the incorporation of $n-6$ and $n-3$ fatty acids into the chick from the egg (means $\pm S D)$. * $(n-6)$, different from the fish and linseed oil diets, $p=0.007 ;{ }^{*}(\mathrm{n}-3)$, different from the soy, fish, and linseed oil diets at $p=0.005$.

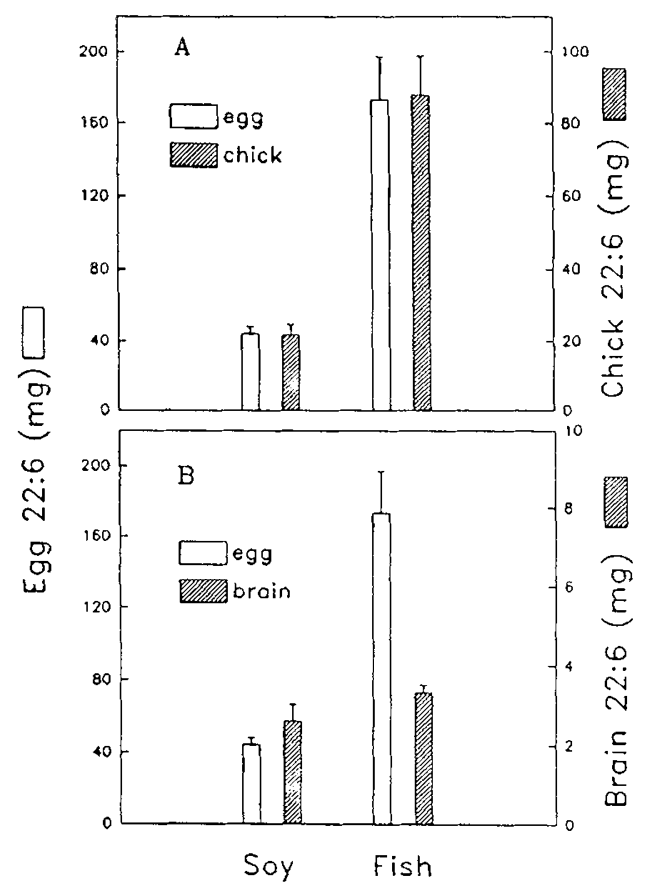

Fig. 2. Effect of egg DHA level on the amount of DHA deposited in the chick body $(A)$ and brain $(B)$ (means $\pm \mathrm{SD}$ ).

\section{DISCUSSION}

Through various mechanisms, animals attempt to adapt to nutritionally inadequate diets. For example, mammalian tissues require polyunsaturated fatty acids, such as arachidonic acid and 


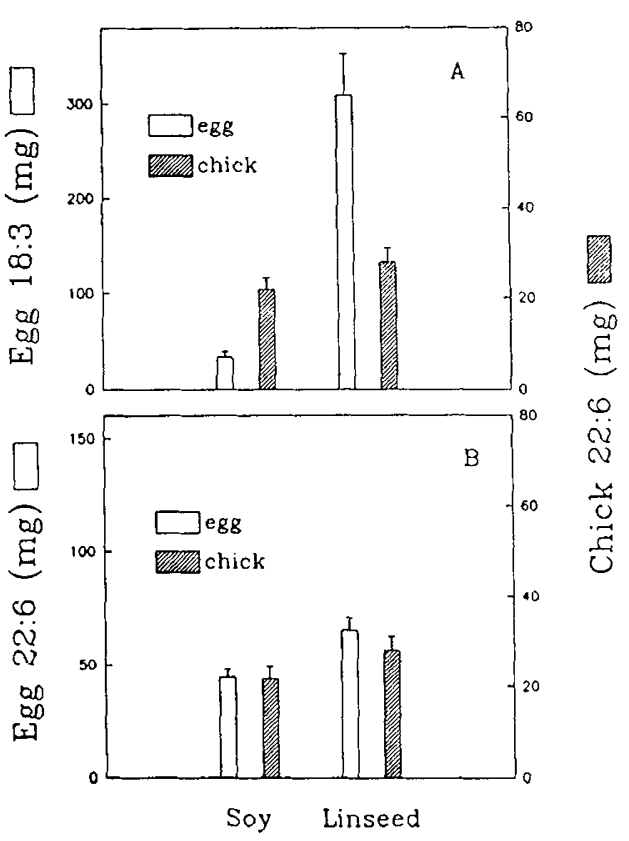

Fig. 3. Effect of egg 18:3 $(A)$ and DHA $(B)$ levels on the amount of DHA deposited in the chick (means $\pm \mathrm{SD}$ ).

DHA, for growth and membrane maintenance. When a fat-free or fat-deficient diet is eaten, the body attempts to compensate for the lack of $n-6$ and $n-3$ polyunsaturated fatty acids by synthesizing a polyunsaturated fatty acid of the n-9 family, namely 5,8,1 1 -eicosatrienoic acid [20:3(n-9)]. When animals are fed a diet deficient in $n-3$ fatty acids, the body compensates for the lack of needed DHA by increasing the synthesis of a longchain polyunsaturated fatty acid of the $n-6$ family, namely 4,7,10,13,16-docosapentaenoic acid [22:5(n-6)]. In our study, the developing chick embryo responded to a short supply of essential $\mathrm{n}-6$ or $\mathrm{n}-3$ fatty acids in the yolk by increasing the percentage of the scarce fatty acid that was incorporated from the egg. Thus, less of the fatty acid in short supply was shunted to oxidative pathways to supply energy for embryo formation and more was incorporated into the tissues. It has been estimated that in excess of $90 \%$ of the energy requirement of the chick embryo is derived from oxidation of yolk lipid fatty acids during development, there being little carbohydrate in eggs $(11,17)$.

This diet-induced difference in the metabolism of fatty acids by the embryo is in addition to the diet-independent preference for sparing of certain fatty acids, especially $n-6$ fatty acids. Leyton et al. (20) have also found a difference in the treatment of various fatty acids by the whole body. In their study, rats oxidized fatty acids differently, depending generally on chain length and degree of unsaturation. This differential oxidation phenomenon may be a contributing factor to net incorporation observed from egg to chick in the present study.

Comparing the fatty acid composition of egg yolk triglyceride and phospholipids with that of the 20-d chick embryo, Isaacks et al. (21) concluded that the polyunsaturated acids of egg yolk triglyceride and phospholipid appear to be preferentially utilized in the development of the chick embryo. Analyzing the fatty acid composition of various phospholipids in the unincubated egg and in eggs incubated for 13,15, 17, 19, and $21 \mathrm{~d}$, Noble and Moore (22) suggested that the developing embryo preferentially absorbs from the yolk a phosphatidylethanolamine fraction that is relatively rich in DHA. On the other hand, Bordoni et al. (23) concluded that lipid absorption did not favor any fatty acid. In our study, we found preferential absorption of both arachidonic acid and DHA from yolk lipids during chick embryo formation under a variety of dietary conditions.

The content of essential n- 6 and n-3 fatty acids in the egg and, in turn, in the chick was proportional to the amounts in the diet of the laying hen. However, although the essential fatty acid content of the diet of the laying hen had a significant effect on the fatty acid composition of the brain of the newborn chick, this effect was not proportional. For example, greatly increasing the amount of DHA or DHA precursor in the egg led to only a moderate increase in brain DHA. Undoubtedly, the phospholipid membranes of the normal brain have an appropriate fatty acid composition, and a large increase in the proportion of DHA may not be compatible with optimal functioning. This optimal fatty acid composition is probably regulated through selective metabolism of given fatty acids or regulation of uptake into tissues such as the brain (24).

Despite the great increase in levels of $18: 3(n-3)$ in the tissues of the linseed oil chicks, no meaningful increase was seen in tissue levels of the 18:3(n-3) metabolite DHA. The small increase in tissue DHA that was observed in the linseed oil chicks could be completely explained by the small increase in preformed DHA that was transferred into the egg yolk by the hens fed the linseed oil diet. This is consistent with studies in the growing chick (25) that showed dietary $18: 3(n-3)$ to be less effective than preformed DHA at supporting deposition of DHA in nervous tissue.

The dietary requirement for $\mathrm{n}-3$ fatty acids has been a matter

Table 3. Effect of diet on fatty acid composition (weight \%) of egg yolk and chick yolk sac contents*

\begin{tabular}{|c|c|c|c|c|c|c|c|c|c|c|}
\hline & \multicolumn{2}{|c|}{$\begin{array}{l}\text { Control } \\
(n=4)\end{array}$} & \multicolumn{2}{|c|}{$\begin{array}{l}\text { Safflower oil } \\
\quad(n=6)\end{array}$} & \multicolumn{2}{|c|}{$\begin{array}{l}\text { Soy oil } \\
(n=5)\end{array}$} & \multicolumn{2}{|c|}{$\begin{array}{l}\text { Fish oil } \\
(n=6)\end{array}$} & \multicolumn{2}{|c|}{$\begin{array}{l}\text { Linseed oil } \\
\quad(n=6)\end{array}$} \\
\hline & Egg & Yolk sac & Egg & Yolk sac & Egg & Yolk sac & Egg & Yolk sac & Egg & Yolk sac \\
\hline Saturated & $38.8 \pm 0.9$ & $35.9 \pm 2.5$ & $35.2 \pm 1.5$ & $34.4 \pm 1.8$ & $35.5 \pm 0.8$ & $35.7 \pm 0.8$ & $43.1 \pm 4.2$ & $40.8 \pm 1.6$ & $36.5 \pm 1.2$ & $36.1 \pm 1.8$ \\
\hline $\begin{array}{l}\text { Mono- } \\
\text { unsaturated }\end{array}$ & $45.5 \pm 0.6$ & $47.7 \pm 1.2$ & $28.5 \pm 1.3$ & $29.6 \pm 1.0$ & $36.9 \pm 0.6$ & $38.5 \pm 0.5$ & $43.8 \pm 0.4$ & $47.2 \pm 1.2$ & $39.3 \pm 1.1$ & $41.2 \pm 1.0$ \\
\hline $\begin{array}{l}\text { Poly- } \\
\text { unsaturated }\end{array}$ & $16.2 \pm 1.5$ & $15.4 \pm 1.3$ & $36.0 \pm 0.9$ & $35.2 \pm 2.3$ & $27.0 \pm 0.8$ & $25.9 \pm 1.2$ & $14.4 \pm 1.1$ & $11.1 \pm 0.8$ & $22.8 \pm 0.9$ & $21.3 \pm 1.6$ \\
\hline Total n-6 & $15.2 \pm 1.5$ & $14.4 \pm 1.3$ & $35.8 \pm 0.9$ & $34.8 \pm 2.9$ & $24.4 \pm 0.7$ & $24.0 \pm 0.8$ & $2.9 \pm 0.6$ & $2.9 \pm 0.7$ & $10.5 \pm 0.4$ & $10.6 \pm 0.7$ \\
\hline $18: 2(n-6)$ & $12.8 \pm 0.5$ & $12.8 \pm 0.6$ & $31.9 \pm 0.6$ & $32.2 \pm 1.9$ & $22.0 \pm 0.8$ & $22.0 \pm 0.8$ & $1.9 \pm 0.6$ & $2.1 \pm 0.5$ & $9.3 \pm 0.1$ & $9.5 \pm 0.6$ \\
\hline $20: 4(n-6) \dagger$ & $1.8 \pm 0.1$ & $1.2 \pm 0.2$ & $2.5 \pm 0.2$ & $1.6 \pm 0.2$ & $2.1 \pm 0.1$ & $1.4 \pm 0.1$ & $0.7 \pm 0.0$ & $0.6 \pm 0.1$ & $0.8 \pm 0.1$ & $0.6 \pm 0.1$ \\
\hline $22: 4(n-6)$ & $0.1 \pm 0.0$ & $0.1 \pm 0.0$ & $0.2 \pm 0.0$ & $0.1 \pm 0.1$ & $0.1 \pm 0.1$ & & $0.2 \pm 0.0$ & $0.2 \pm 0.1$ & $0.1 \pm 0.1$ & $0.1 \pm 0.1$ \\
\hline $22: 5(n-6)$ & $0.3 \pm 0.2$ & & $0.4 \pm 0.1$ & $0.1 \pm 0.1$ & $0.1 \pm 0.0$ & & $0.1 \pm 0.1$ & & $0.5 \pm 0.1$ & \\
\hline Total n-3 & $0.9 \pm 0.1$ & $0.6 \pm 0.2$ & $0.2 \pm 0.1$ & $0.1 \pm 0.1$ & $2.6 \pm 0.1$ & $1.7 \pm 0.1$ & $11.5 \pm 0.7$ & $7.7 \pm 0.7$ & $12.0 \pm 0.4$ & $10.8 \pm 1.0$ \\
\hline $18: 3(n-3)$ & $0.3 \pm 0.0$ & $0.3 \pm 0.1$ & $0.1 \pm 0.0$ & $0.1 \pm 0.0$ & $1.3 \pm 0.1$ & $1.4 \pm 0.1$ & $0.3 \pm 0.1$ & $0.3 \pm 0.1$ & $9.1 \pm 0.4$ & $9.4 \pm 1.0$ \\
\hline $20: 5(n-3)$ & & & & & & & $2.5 \pm 0.2$ & $2.1 \pm 0.1$ & $0.4 \pm 0.1$ & $0.2 \pm 0.1$ \\
\hline $22: 5(n-3)$ & $0.1 \pm 0.1$ & & & & $0.1 \pm 0.1$ & $0.1 \pm 0.1$ & $1.8 \pm 0.2$ & $1.7 \pm 0.2$ & $0.5 \pm 0.1$ & $0.4 \pm 0.1$ \\
\hline $22: 6(n-3) \dagger$ & $0.5 \pm 0.1$ & $0.2 \pm 0.1$ & $0.1 \pm 0.0$ & $0.0 \pm 0.0$ & $1.2 \pm 0.1$ & $0.2 \pm 0.1$ & $6.7 \pm 0.6$ & $3.4 \pm 0.6$ & $1.9 \pm 0.3$ & $0.6 \pm 0.1$ \\
\hline
\end{tabular}

* Means \pm SD.

$\uparrow$ Yolk sac different from egg yolk for all diets, $p<0.001$. 
of some discussion, with little hard data $(26,27)$. Our observation of a relative sparing of $n-3$ fatty acids during development of chicks from the low n-3 fatty acid groups (control and safflower oil diets) may mean that $n-3$ fatty acid levels in these two diets were below the "requirement" for the developing chick. Thus, these chicks may have metabolically sensed that the essential n3 fatty acids were in short supply, and may have attempted to conserve scarce resources by channeling less of these fatty acids into oxidative pathways. The lack of a sparing response in chicks from hens fed the soybean oil diet may mean that the amount of $n-3$ fatty acids in the egg yolk met or exceeded the requirement. Thus, one can estimate the requirement for $n-3$ fatty acids in the developing chick embryo as being between the levels of $n-3$ fatty acids present in eggs containing: 1) the lowest amount of n-3 fatty acids that did not evoke a sparing response and 2) the highest amount of $n-3$ fatty acids that did evoke a sparing response. This would correspond to the soybean and control diets, containing an average of 84 and $26 \mathrm{mg}$ of n-3 fatty acids per egg, respectively. With a calculated average of $65.9 \mathrm{kcal}$ per egg in our study (28), and assuming $9 \mathrm{kcal} / \mathrm{g}$ fatty acid, the amount of $\mathrm{n}-3$ fatty acids in the soybean and control diets equates to 1.1 and $0.4 \%$ of energy, respectively. Thus, the requirement for $\mathrm{n}-3$ fatty acids can be estimated as being between 0.4 and $1.1 \%$ of energy.

For $\mathrm{n}-6$ fatty acids, a sparing response was observed in chicks fed the fish and linseed oil diets. By the same reasoning as given above for $\mathrm{n}-3$ fatty acids, the estimated requirement for $\mathrm{n}-6$ fatty acids lay between the linseed and control diets, equating to 4.8 to $6.2 \%$ of energy, respectively. This is somewhat higher than $3.8 \%$ of energy, the requirement for linoleic acid measured in 1to 3-wk-old chicks from hens fed diets low in linoleic acid (29). These values for $n-3$ and $n-6$ requirements for the developing chick would suggest an optimal "dietary" ratio of n-6 to n-3 fatty acids of between 5 and 14 .

This study may have several possible implications for the diet of human infants. The first is that the ratio of $n-6$ to $n-3$ fatty acids is a useful way of expressing a dietary recommendation because this ratio appears to have a relationship to DHA concentrations in the brain from the data in this paper. Very high ratios $(>150: 1)$, as in diets based on safflower, sunflower, or peanut oils, produce DHA tissue depletion and retinal abnormalities in animals (3), and high ratios in the diets of human infants may reduce visual acuity and lead to abnormalities in the electroretinogram (30). Secondly, the absolute amounts of n-3 fatty acids in infant formulas are important. Our view is that the n-3 fatty acids should approximate the amounts and kinds present in human milk. In human milk, n-3 fatty acids (including small amounts of preformed DHA) normally represent $0.7-1.3 \%$ of calories, and the n-6 to n-3 ratio is $4: 1$ to $10: 1(31,32)$. We would suggest that these values be used as a guide for the preparation of human infant formulas, and that DHA should be included. Retinal and brain DHA accumulation may not be optimal when only $\alpha$-linolenic acid [18:3(n-3)] is present in the diet. It should be noted that several currently marketed infant formulas fail to meet the $n-6 / n-3$ ratio criteria and none of them contain any DHA. We appreciate the controversial aspects of these suggestions and anticipate that there will not be universal agreement. There was, however, a general consensus of views similar to ours at a recent meeting about $n-3$ fatty acid requirements (33).

Acknowledgments. The authors thank Julie D. Corliss for technical assistance and David Wilson and Dr. Gary J. Sexton for help with statistical analysis of the data.

\section{REFERENCES}

1. Burr GO. Burr MM 1929 A new deficiency disease produced by the rigid exclusion of fat from the diet. J Biol Chem 82:345-367
2. Burr GO, Burr MM 1930 On the nature and role of the fatty acids essential in nutrition. J Biol Chem 86:587-621

3. Neuringer M. Anderson GJ, Connor WE 1988 The essentiality of n-3 fatty acids for the development and function of the retina and brain. Annu Rev Nutr 8:517-541

4. Yamamoto N, Saitoh M, Moriuchi A, Nomura M, Okuyama H 1987 Effect of dietary $\alpha$-linolenate/linoleate balance on brain lipid compositions and learning ability of rats. $J$ Lipid Res 28:144-151

5. Yamamoto N, Hashimoto A, Takemoto Y, Okuyama H, Nomura M, Kitayima R. Togashi T, Tamai Y 1988 Effect of the dietary $\alpha$-linolenate/linoleate balance on lipid compositions and learning ability of rats. II. Discrimination process, extinction process, and glycolipid compositions. J Lipid Res 29:1013-1021

6. Bourre JM, Francois M, Youyou A, Dumont O, Piciotti M. Pascal G. Durand G 1989 The effects of dietary alpha-linolenic acid on the composition of nerve membranes, enzymatic activity, amplitude of electrophysiological parameters, resistance to poisons and performance of learning tasks in rats. J Nutr 1 19:1880-1892

7. Neuringer M, Connor WE, Lin DS, Barstad L. Luck SJ 1986 Biochemical and functional effects of prenatal and postnatal omega-3 fatty acid deficiency on retina and brain in rhesus monkeys. Proc Natl Acad Sci USA 83:4021-4025

8. Neuringer M, Connor WE, Van Patten C, Barstad L 1984 Dietary omega-3 fatty acid deficiency and visual loss in infant rhesus monkeys. J Clin Invest 73:272-276

9. Connor WE, Neuringer M, Barstad L, Lin DS 1984 Dietary deprivation of linolenic acid in rhesus monkeys: effects on plasma and tissue fatty acid composition and on visual function. Trans Assoc Am Physicians 97:1-9

10. Reisbick S, Neuringer M, Hasnain R, Connor WE 1990 Polydipsia in rhesus monkeys deficient in omega-3 fatty acids. Physiol Behav 47:315-323

11. Romanoff AL 1967 Biochemistry of the avian embryo. John Wiley, New York

12. Anderson GJ, Connor WE Corliss JD, Lin DS 1989 Rapid modulation of the $\mathrm{n}-3$ docosahexaenoic acid levels in the brain and retina of the newly hatched chick. J Lipid Res 30:433-441

13. Folch J, Lees MB, Sloane-Stanley GH 1957 A simple method for the isolation and purification of total lipids from animal tissues. J Biol Chem 226:497509

14. Miljanich GP, Sklar LA, White DL, Dratz EA 1979 Disaturated and dipolyunsaturated phospholipids in bovine retinal rod outer segment disk membrane. Biochim Biophys Acta 552:294-303

15. Miyamoto K, Stephanides LM, Bernsohn J 1967 Incorporation of [1-14C] linoleate and linolenate into polyunsaturated fatty acids of phospholipids of the embryonic chick brain. J Neurochem 14:227-237

16. Noble RC, Shand JH 1985 Unsaturated fatty acid compositional changes and desaturation during the embryonic development of the chicken (gallus domesticus). Lipids 20:278-282

17. Freeman BM, Vince MA 1974 Development of the avian embryo. Chapman and Hall, London

18. Winer BJ 1971 Statistical Principles in Experimental Design. McGraw-Hill, New York

19. Miller RG 1966 Simultancous Statistical Inference. McGraw-Hill, New York

20. Leyton J, Drury PJ, Crawford MA 1987 Differential oxidation of saturated and unsaturated fatty acids in vivo in the rat [published erratum appears in Br J Nutr 1987 Sep:58(2):following 331]. Br J Nutr 57:383-393

21. Isaacks RE, Davies RE, Ferguson TM, Reiser R, Couch JR 1964 Studies on avian fat composition. 2 . The selective utilization of fatty acids by the chick embryo. Poult Sci 43:113-120

22. Noble RC, Moore JH 1965 Metabolism of the yolk phospholipids by the developing chick embryo. Can J Biochem 43:1677-1686

23. Bordoni A, Cocchi M, Lodi R, Turchetto E, Ruggeri F 1986 Metabolism and distribution of linoleic and $x$-linolenic acid derivatives in chick embryo development. Prog Lipid Res 25:407-411

24. Anderson GJ, Connor WE 1988 Uptake of fatty acids by the developing rat brain. Lipids 23:286-290

25. Anderson GJ, Connor WE, Corliss JD 1990 Docosahexaenoic acid is the preferred dietary n-3 fatty acid for the development of the brain and retina. Pediatr Res 27:89-97

26. Simopoulos AP 1989 Summary of the NATO advanced workshop on dietary omega 3 and omega 6 fatty acids: biological effects and nutritional essentiality. J Nutr 1 19:521-528

27. Food and Nutrition Board (National Research Council) 1989 Recommended Dietary Allowances. National Academy Press, Washington, DC

28. Pennington JAT 1989 Bowes \& Churche's Food Values of Portions Commonly Used. Lippincott, Philadelphia

29. Hopkins DT, Nesheim MC 1967 The linoleic acid requirement of chicks. Poult Sci 46:872-881

30. Uauy RD, Birch DG. Birch EE. Tyson JE, Hoffman DR 1990 Effect of dietary omega-3 fatty acids on retinal function of very-low-birth weight neonates. Pediatr Res 28:485-492

31. Gibson RA, Kneebone GM 1981 Fatty acid composition of human colostrum and mature breast milk. Am J Clin Nutr 34:252-257

32. Jansson L, Akesson B. Holmberg L 1981 Vitamin E and fatty acid composition of human milk. Am J Clin Nutr 34:8-13

33. Simopoulos AP (ed) 1991 Health effects of omega-3 polyunsaturated fatty acids in seafood. World Rev Nutr Diet 66:118-132 